\title{
Spatial Heterogeneity of Leaf Wetness Duration in Apple Trees and Its Influence on Performance of a Warning System for Sooty Blotch and Flyspeck
}

\author{
J. C. Batzer and M. L. Gleason, Department of Plant Pathology, S. E. Taylor, Department of Agronomy, and \\ K. J. Koehler, Department of Statistics, Iowa State University, Ames 50011; and J. E. B. A. Monteiro, Agrometeo- \\ rology Group, Department of Exact Sciences, ESALQ, University of São Paulo, 13418-900 Piracicaba, SP, Brazil
}

\begin{abstract}
Batzer, J. C., Gleason, M. L., Taylor, S. E., Koehler, K. J., and Monteiro, J. E. B. A. 2008. Spatial heterogeneity of leaf wetness duration in apple trees and its influence on performance of a warning system for sooty blotch and flyspeck. Plant Dis. 92:164-170.

To determine the effect of sensor placement on the performance of a disease-warning system for sooty blotch and flyspeck (SBFS), we measured leaf wetness duration (LWD) at 12 canopy positions in apple trees, then simulated operation of the disease-warning system using LWD measurements from different parts of the canopy. LWD sensors were placed in four trees within one Iowa orchard during two growing seasons, and in one tree in each of four orchards during a single growing season. The LWD measurements revealed substantial heterogeneity among sensor locations. In all data sets, the upper, eastern portion of the canopy had the longest mean daily LWD, and was the first site to form dew and the last to dry. The lower, western portion of the canopy averaged about $3 \mathrm{~h}$ less LWD per day than the top of the canopy, and was the last zone where dew formed and the first to dry off. On about $25 \%$ of nights when dew occurred in the top of the canopy, no dew formed in the lower, western canopy. Intracanopy variability of LWD was more pronounced when dew was the sole source of wetness than on days when rainfall occurred. Daily LWD in the upper, eastern portion of the canopy was slightly less than reference measurements made at a $0.7-\mathrm{m}$ height over turfgrass located near the orchard. When LWD measurements from several canopy positions were input to the SBFS warning system, timing of occurrence of a fungicide-spray threshold varied by as much as 30 days among canopy positions. Under Iowa conditions, placement of an LWD sensor at an unobstructed site over turfgrass was a fairly accurate surrogate for the wettest part of the canopy. Therefore, such an extra-canopy LWD sensor might be substituted for a within-canopy sensor to enhance operational reliability of the SBFS warning system.
\end{abstract}

Additional keyword: microclimate

The sooty blotch and flyspeck (SBFS) fungal complex poses a major threat to apple production in humid climates worldwide. These fungi blemish the apple cuticle, preventing apple fruit from being marketable as fresh fruit. Apple fruit with SBFS usually are sold for processing, reducing the crop value by up to $90 \%(2,26)$. Growers control SBFS by applying fungicides every 10 to 14 days from soon after bloom until shortly before harvest (26) at a cost of approximately $\$ 15$ to 25 per acre per spray (18).

A conventional, calendar-based protectant fungicide spray program for SBFS management may not be sustainable (1).

Corresponding author: M. Gleason

E-mail: mgleason@iastate.edu

Accepted for publication 16 August 2007.

doi:10.1094/PDIS-92-1-0164

(C) 2008 The American Phytopathological Society
Several broad-spectrum fungicides that are widely used against SBFS can present potential health risks to applicators and consumers $(3,26)$. In the United States, health and environmental concerns led to restriction of the ethylene bisdithiocarbamate (EBDC) fungicides to early-season use in 1990, removing the most potent and affordable weapons against SBFS (26). Growers experience sporadic control failures related to poor fungicide coverage, inadequate pruning, and periods when environmental conditions are highly favorable for SBFS development (5).

Disease-warning systems help growers to reduce input costs by minimizing the number of fungicide applications while maintaining acceptable disease control. The most widely used SBFS diseasewarning system is based on knowledge of the ecology of predominant SBFS fungi in North Carolina. Brown and Sutton (4) observed that the first signs of SBFS usually occurred after 273 cumulative hours of leaf wetness duration (LWD), starting from the first rain that occurred 10 days after petal fall and counting only periods of $\geq 4$ $\mathrm{h}$ duration. They concluded that applying benzimidazole fungicides 200 to 225 LWD $\mathrm{h}$ after this starting point, followed by fungicide sprays every 10 to 14 days until harvest, resulted in apple fruit free of SBFS blemishes while saving several sprays compared with a conventional schedule $(4,15,19)$. The Brown-SuttonHartman version of this warning system, using a 175-h LWD threshold between application of the first-cover ( 7 to 10 days after petal fall) and second-cover fungicide sprays, has been tested in Massachusetts, Kentucky, and the Midwest and often saves two or more fungicide sprays per season $(1,6,9-11,23,24)$.

The Brown-Sutton-Hartman warning system has been widely implemented using LWD measurements made at a $1.5-\mathrm{m}$ height within the canopy of apple trees in monitored orchards $(1,17)$. In the Midwest, however, this system sometimes failed to provide acceptable control of SBFS (1). Examination of instances of control failures revealed no consistent association with possible contributing factors such as inadequate pruning, low-volume spraying, or delayed response to spray advisories (26; M. L. Gleason and J. C. Batzer, unpublished data). It is possible that spatial heterogeneity of LWD measurements within the canopy could influence the performance of the warning system, but this possibility has not been investigated.

Dew is a major contributor to LWD in an apple canopy in most humid regions (12). Dew formation in crop canopies is influenced by leaf area, plant architecture, arrangement of plants in the field, and crop height, and is mediated by temperature, vapor pressure, incoming short- and longwave radiation, and wind speed $(7,12)$. The top of the plant canopy tends to experience the greatest LWD in humid climates, whereas the middle of the canopy tends to be the wettest in semiarid climates $(14,25,27)$. For example, Penrose and Nicol (20) found that LWD in semiarid Australian apple orchards was greatest in the center of the canopy. Decreased wind speed in the lower canopy also may delay drying of lower leaves $(13,14)$. Sentelhas 
et al. (21) characterized LWD variability within the canopy of several different crops. The top of apple and corn canopies had longer LWD than the lower portions of the canopy, whereas the lower canopy of young coffee plants had longer LWD than top positions.

A thorough understanding of the LWD heterogeneity within a crop canopy is essential for implementing a disease-warning system that relies on LWD data as inputs. The objectives of this study were to (i) determine spatial heterogeneity of LWD within apple trees in Iowa orchards and (ii) simulate operation of an SBFS diseasewarning system from LWD measured in different parts of the canopy.

\section{MATERIALS AND METHODS}

Study sites. LWD data were collected from the canopy of apple trees during three growing seasons at four central-Iowa orchards. Mature (3.5 to $5 \mathrm{~m}$ tall) semidwarf trees (cv. Golden Delicious) were well pruned and under conventional management for insects and diseases (8). Study sites were in Gilbert, (42.1087, -93.6500, north-south rows), Cambridge (41.8972, -93.5204, east-west rows), Jefferson (41.9933, -94.4292, east-west rows), and Fort Dodge (42.5075, -94.2531, northsouth rows). The Gilbert and Cambridge orchards were on upland, level sites, whereas Jefferson and Fort Dodge were on the slopes of wooded river valleys. In Gilbert, sensors were placed in three trees from 5 July to 30 August 2000, in four trees from 9 May to 18 September 2001, and in a single tree from 5 May to 30 September 2003. Single trees in Fort Dodge, Jefferson, and Cambridge were monitored from 5 May to 30 September 2003. Two additional LWD sensors were erected 0.7 $\mathrm{m}$ above mowed turfgrass, facing north, on an unobstructed site located 50 to $100 \mathrm{~m}$ from apple trees at Fort Dodge, Cambridge, and Gilbert.

Sensors. Flat, printed-circuit sensors (model 237; Campbell Scientific, Logan, UT) were used to measure LWD. Sensors were painted with off-white latex paint of proprietary composition (R. Olson, Savannah, GA, personal communication) to increase sensitivity to small droplets of moisture and heat treated $\left(60\right.$ to $70^{\circ} \mathrm{C}$ for $12 \mathrm{~h}$ ) to remove or deactivate hygroscopic components of the paint (16). Sensors were mounted on the end of a section of PVC pipe at an inclination of $45^{\circ}$ to horizontal. Free water on the sensors was detected by measuring the electrical impedance of the grid using a datalogger (model CR10; Campbell Scientific). Using measurements made at 5-min intervals, daily LWD was computed as the total amount of time the sensor detected wetness in the 24$\mathrm{h}$ period beginning at 1100 hours and ending at 1100 hours the following day.

Prior to deployment, LWD wetness sensors were compared with each other for 5 days at a $0.7-\mathrm{m}$ height over turfgrass at three impedance thresholds (500, 1,000 and $1,500 \mathrm{k} \Omega$ ). This preliminary trial indicated that a $1,000-\mathrm{k} \Omega$ threshold had the least hourly LWD variability and was highly sensitive to wetness. No significant differences in hourly LWD were found within the four groups of 12 sensors $(P$ values of $0.9984,0.9999,0.9999$, and 0.9840 ) using the $1,000-\mathrm{k} \Omega$ threshold. Therefore, sets of sensors used in the field studies were equivalent in wetness sensitivity and differences among sensor readings in apple tree canopies were attributed to variations in microenvironment.

Precipitation was recorded by tippingbucket rain gauges (model TE525; Campbell Scientific) located at an unobstructed site adjacent to each orchard.

Sensor locations in apple tree canopies. Hourly LWD averages were obtained at 12 canopy positions within each apple tree (Fig. 1). Sensors were installed facing north, at an inclination of $45^{\circ}$ to horizontal, at four horizontal positions, approximately $0.5 \mathrm{~m}$ apart, along an east-west transect, at heights of approximately $3.5 \mathrm{~m}$ (upper canopy), $2.5 \mathrm{~m}$ (middle canopy), and $1.2 \mathrm{~m}$ (lower canopy).

Data analysis. To examine patterns within a single orchard, the "single-orchard" data set was obtained from Gilbert during the 2000, 2001, and 2003 growing seasons. To examine patterns across orchards, a "multiple-orchard" data set was compiled during the 2003 growing season at Gilbert, Cambridge, Jefferson, and Fort Dodge. Daily data sets were partitioned into norain days (defined as days with no mea- sured rainfall) and rain days (defined as days with measured rainfall $\geq 0.25 \mathrm{~mm}$ ).

The hypothesis that all canopy positions had equivalent daily LWD was evaluated using an $F$ test, and least squares means then were compared using Fisher's test of least significant differences for multiple comparisons. The SAS Mixed procedure (SAS Institute, Inc. Cary, NC) with the unstructured correlation option was used to incorporate correlations corresponding to positions within the tree canopy. Responses on different days were assumed to be independent. Canopy LWD microclimates were delineated using the contour plot feature of SigmaPlot 8.0 (SigmaPlot for Windows, SPSS Inc.). Multiple comparisons of sensor locations were conducted for both data sets. Daily LWD data from sensors over turfgrass were correlated with data from sensors in the upper eastern and lower western portions of the canopies of the four trees at Gilbert during 2001, and with the multiple orchards data set.

Timing of dew onset and dry-off within the canopy also was assessed for the four trees at Gilbert in 2001. Mean dew onset and dry-off times within the canopies of the four trees were calculated for 69 dew events. For each dew event, times of dew onset and dry-off at each sensor location were compared with the first occurrence of these events within the canopy. Dew onset was initiated when the first sensor in any canopy location recorded wetness for $>30$ min. Dry-off of a dew event began when the first sensor in any canopy location became dry for $>30 \mathrm{~min} / \mathrm{h}$ and then remained dry for at least $3 \mathrm{~h}$.

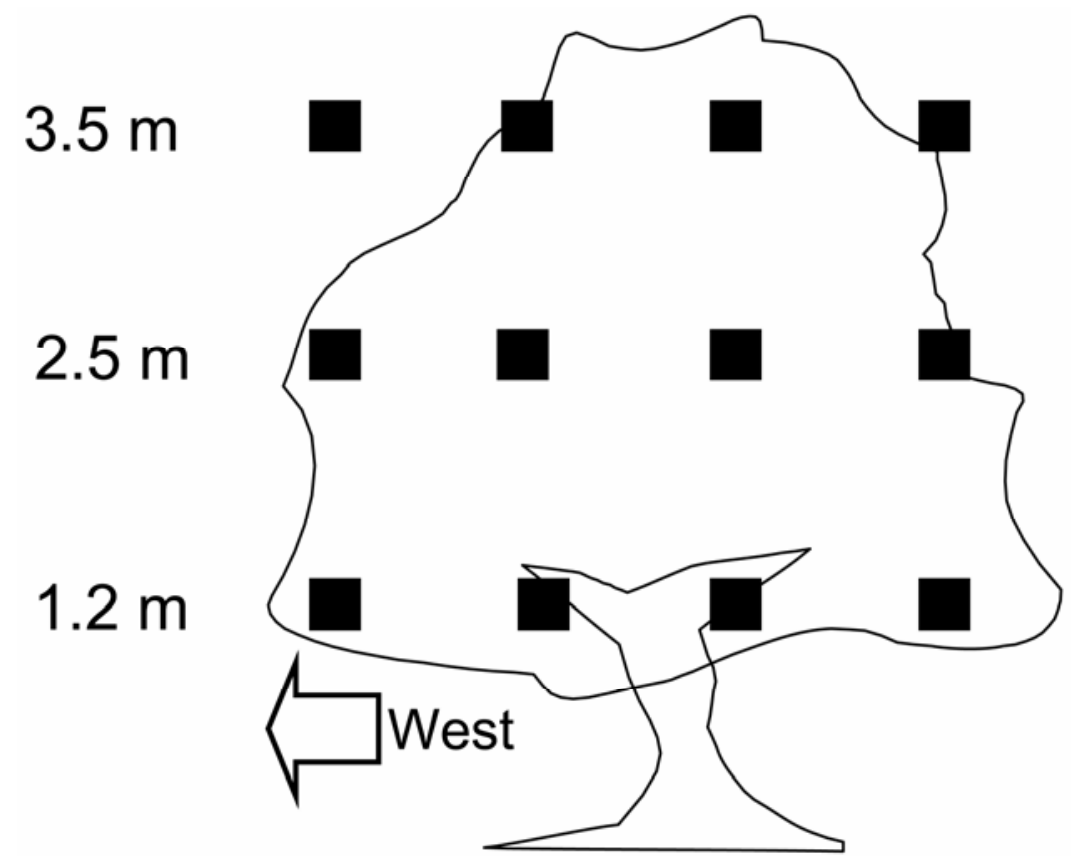

Fig. 1. Location of leaf wetness duration (LWD) sensors in apple tree canopies. Electronic sensors were mounted facing north at an inclination of $45^{\circ}$ to horizontal. Sensors were placed in apple trees at four horizontal positions, approximately $0.5 \mathrm{~m}$ apart, along an east-west transect, at heights of approximately $3.5 \mathrm{~m}$ (upper canopy), $2.5 \mathrm{~m}$ (middle canopy), and $1.2 \mathrm{~m}$ (lower canopy). Sensors are denoted by rectangles. 
Simulation of a SBFS warning system. We simulated operation of the BrownSutton-Hartman SBFS warning system $(4,10,11,23,24)$ to determine the timing of the second-cover fungicide spray. This warning system advises applying the second-cover fungicide spray when cumulative LWD following application of the first-cover spray reaches $175 \mathrm{~h}$. The firstcover spray typically is applied 7 to 10 days after petal fall. In the present study, wetness hours were accumulated based on the following decision rules: (i) scored as dry when hourly LWD was detected for $<30 \mathrm{~min} / \mathrm{h}$ the hour, and scored as wet when wetness was detected for $\geq 30 \mathrm{~min} / \mathrm{h}$ the hour; (ii) wetness periods were counted only when $\geq 4 \mathrm{~h}$; and (iii) wetness periods ended when $\geq 2$ consecutive dry $\mathrm{h}$ were recorded (1). We used the actual first-cover spray dates determined by apple phenology in the orchard: 29 May 2001 (Gilbert), 24 May 2003 (Gilbert, Cambridge, and Fort Dodge), and 20 May 2003 (Jefferson).

\section{RESULTS}

Spatial variation of $L W D$ within apple tree canopies. The hypothesis that means of daily LWD among the canopy measurement sites were equal (Tables 1 and 2) was rejected based on the results of the $F$ test, and it was assumed that LWD was not homogeneous throughout the canopy. For both data sets, daily LWD was longest in

Table 1. Analysis of variance of daily leaf wetness duration (LWD) for the single-orchard data set ${ }^{\mathrm{a}}$

\begin{tabular}{|c|c|c|c|c|}
\hline \multirow[b]{2}{*}{ Source } & \multirow[b]{2}{*}{ df } & \multicolumn{3}{|c|}{$P$ value } \\
\hline & & All days & Rain days $^{b}$ & Non-rain days ${ }^{c}$ \\
\hline \multicolumn{5}{|l|}{ Main effects ${ }^{\mathrm{d}}$} \\
\hline Height $^{e}$ & 2 & $<0.0001$ & $<0.0001$ & $<0.0001$ \\
\hline Interior/exterior $\mathrm{f}^{\mathrm{f}}$ & 1 & 0.2750 & 0.7722 & 0.178 \\
\hline Direction $^{\mathrm{g}}$ & 1 & $<0.0001$ & 0.0178 & $<0.0001$ \\
\hline \multicolumn{5}{|l|}{ Interactions of fixed factors } \\
\hline Height $\times$ interior or exterior & 2 & 0.0002 & 0.5228 & $<0.0001$ \\
\hline Height $\times$ direction & 2 & 0.0005 & 0.2477 & $<0.0001$ \\
\hline Interior or exterior $\times$ direction & 1 & 0.0002 & 0.2193 & $<0.0001$ \\
\hline Height $\times$ interior or exterior $\times$ direction & 2 & 0.0045 & 0.4644 & 0.0012 \\
\hline
\end{tabular}

${ }^{a}$ Data collected during the 2000, 2001, and 2003 growing seasons at a Gilbert, IA orchard. Data include 12 canopy locations within each of four semidwarf trees (cv. Golden Delicious). Trees rows were oriented north-south.

${ }^{b}$ Days with total rainfall $\geq 0.25 \mathrm{~mm}: 7$ days in 2000, 8 days in 2001, and 32 days in 2003 .

${ }^{c}$ Days on which no rainfall was measured and dew was the only source of LWD: 25 days in 2000, 34 days in 2001, and 81 days in 2003.

${ }^{\mathrm{d}}$ Fixed location factors included height, interior or exterior, and direction.

e Upper, middle, and lower canopy.

${ }^{\mathrm{f}}$ Interior versus exterior of canopy.

$\mathrm{g}$ East or west of canopy center.

the upper eastern portion of the tree canopy and shortest in the lower western portion of the tree canopy (Fig. 2).

Single-orchard data set. Differences in LWD among canopy positions were greatest during days where the only source of wetness was from dew (Fig. 2). During norain days, mean daily LWD in the lower western position was $4.5 \mathrm{~h}$ less than in the upper eastern position. In contrast, mean daily LWD in these positions differed by about $2.5 \mathrm{~h}$ during rain days. No-rain days predominated $(72 \%)$ in the growing season. As a result, patterns of spatial variation in LWD observed for no-rain days were similar to patterns for all days on which LWD was measured.

Significant differences $(P<0.0001)$ in daily LWD were detected for height (upper, middle, and lower canopy levels) and direction (east versus west of tree trunk) (Table 1). Differences in daily LWD from east to west were not as pronounced in the upper canopy as in the lower canopy (Fig. 2A). Likewise, differences among heights were less on the outer eastern $(2 \mathrm{~h})$ than the outer western $(4.2 \mathrm{~h})$ canopy positions. At a given canopy height, mean daily LWD tended to be more similar for positions close to the tree trunk than for positions near the periphery of the canopy. Significant interactions of height, direction, and interior or exterior factors were observed for no-rain days but not for days with rain (Table 1).

Multiple-orchard data set. Significant differences $(P<0.0001)$ in LWD were observed among the four orchards in 2003 (Table 2). There were no apparent interactions between orchard and canopy posi-

Table 2. Analysis of variance of daily leaf wetness duration (LWD) for the multiple-orchard data set ${ }^{\mathrm{a}}$

\begin{tabular}{|c|c|c|c|c|}
\hline \multirow[b]{2}{*}{ Source } & \multirow[b]{2}{*}{ df } & \multicolumn{3}{|c|}{$P$ value } \\
\hline & & All days & Rain days $^{b}$ & Non-rain days ${ }^{\mathrm{c}}$ \\
\hline \multicolumn{5}{|l|}{ Main effects ${ }^{d}$} \\
\hline Orchard & 3 & $<0.0001$ & $<0.0001$ & $<0.0001$ \\
\hline Height $^{\mathrm{e}}$ & 2 & $<0.0001$ & $<0.0001$ & $<0.0001$ \\
\hline Direction $^{\mathrm{f}}$ & 1 & $<0.0001$ & 0.0730 & $<0.0001$ \\
\hline Interior or exterior ${ }^{\mathrm{g}}$ & 1 & 0.0122 & 0.3930 & 0.0040 \\
\hline \multicolumn{5}{|l|}{ Interactions of fixed factors } \\
\hline Height $\times$ interior or exterior & 3 & 0.0489 & 0.5869 & 0.0169 \\
\hline Height $\times$ direction & 2 & 0.0011 & 0.2827 & 0.0007 \\
\hline Interior/exterior $\times$ direction & 1 & 0.3638 & 0.5686 & 0.3569 \\
\hline Height $\times$ interior or exterior $x$ direction & 2 & 0.2718 & 0.4415 & 0.3380 \\
\hline \multicolumn{5}{|l|}{ Interactions with orchard } \\
\hline Orchard $\times$ height & 6 & 0.7128 & 0.7208 & 0.7738 \\
\hline Orchard $x$ interior or exterior & 3 & 0.1887 & 0.8433 & 0.0635 \\
\hline Orchard $\times$ direction & 3 & 0.1602 & 0.5203 & 0.0293 \\
\hline Orchard $\times$ height $\times$ interior or exterior & 3 & 0.6972 & 0.9196 & 0.3839 \\
\hline Orchard $\times$ height $\times$ direction & 6 & 0.4399 & 0.5031 & 0.2239 \\
\hline Orchard $x$ interior or exterior $x$ direction & 3 & 0.5878 & 0.7150 & 0.6577 \\
\hline Orchard $\times$ height $\times$ interior or exterior $\times$ direction & 3 & 0.8846 & 0.9254 & 0.5089 \\
\hline \multirow{2}{*}{\multicolumn{5}{|c|}{$\begin{array}{l}\text { a Data collected during the } 2003 \text { growing season data at four Iowa apple orchards. Twelve canopy locations per tree were monitored within single trees a } \\
\text { each orchard. }\end{array}$}} \\
\hline & & & & \\
\hline \multicolumn{5}{|c|}{$\begin{array}{l}\text { ' Days on which no rainfall was measured and dew was the only source of LWD: } 81 \text { days in Gilbert; } 119 \text { days in Cambridge, } 128 \text { days in Jefferson, and } 109 \\
\text { days in Fort Dodge. }\end{array}$} \\
\hline \multirow{2}{*}{\multicolumn{5}{|c|}{$\begin{array}{l}\text { d Orchard (study site) was treated as a random effect; fixed canopy location factors included height, interior or exterior, and direction. } \\
\text { e Upper, middle, and lower canopy. }\end{array}$}} \\
\hline & & & & \\
\hline \multicolumn{5}{|l|}{${ }^{\mathrm{f}}$ East or west of canopy center. } \\
\hline $\mathrm{g}$ Interior versus exterior of canopy. & & & & \\
\hline
\end{tabular}



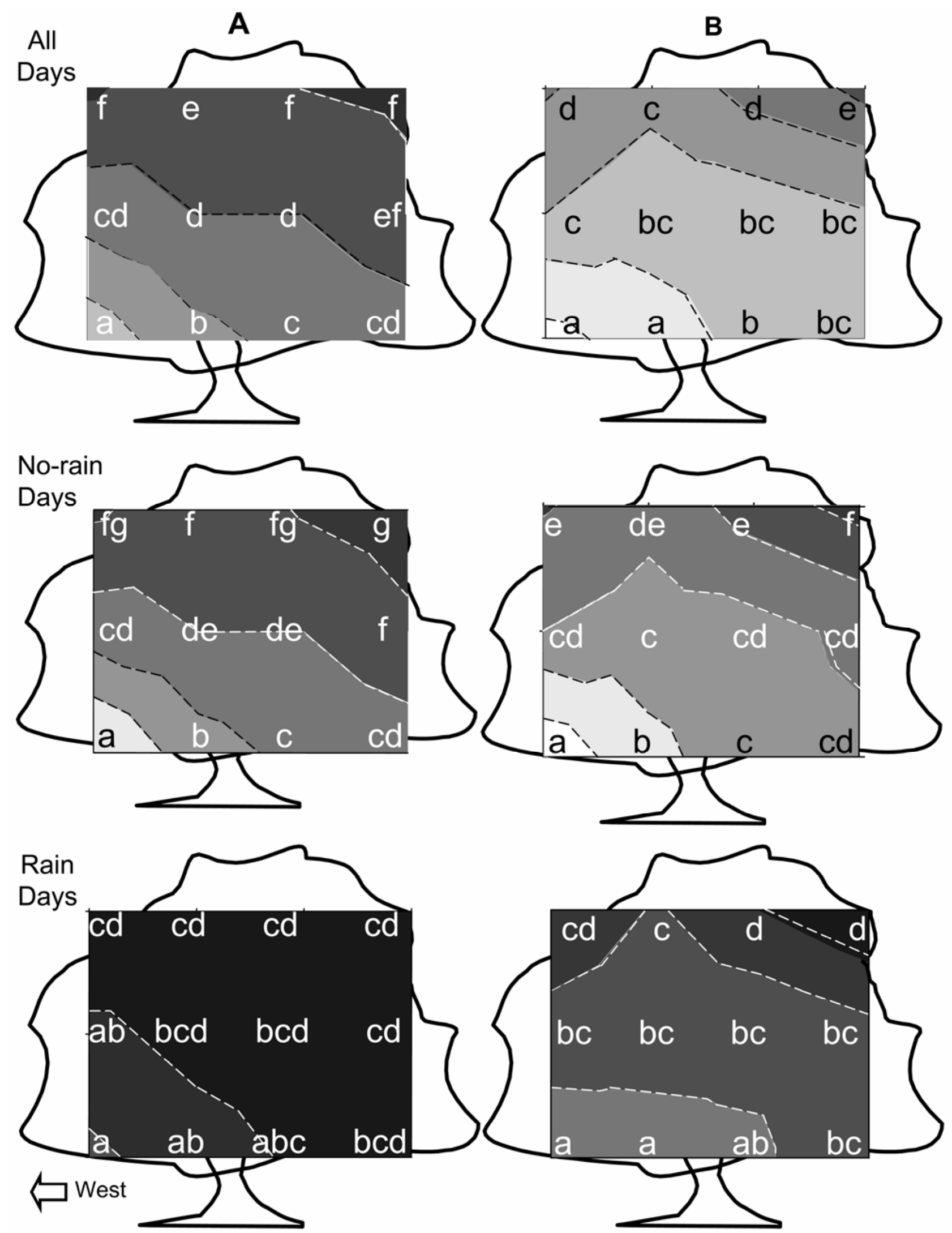

Leaf Wetness Duration Hours
$3-3.9 \square$
4-4.9
5-5.9
6-6.9
7-7.9
8-8.0
9-9.9
10-11

Fig. 2. Statistical comparison of mean daily leaf wetness duration (LWD) among 12 canopy positions in apple trees. A, The single-orchard data set summarizes measurements made at a Gilbert, Iowa orchard in 2000, 2001, and 2003. B, The multiple-orchard data set summarizes measurements from four Iowa orchards in 2003. Daily data sets were partitioned into rain (measured rainfall $\geq 0.25 \mathrm{~mm}$ ) and no-rain days. Dotted lines separate 1-h differences in LWD. Canopy positions that do not share the same letters are significantly different from each other $(P<0.05)$. 
tion, indicating that trees at all study sites had similar patterns of variation in LWD with canopy position. On no-rain days, LWD differed among canopy heights, compass direction, interior versus exterior, and interactions of height-interior or exterior and height-direction were found. On rain days, however, LWD differed only for height and there were no interactions among canopy positions.

As in the single-orchard data set, greater differences among canopy positions were observed for no-rain days than rain days (Fig. 2B). The lower western position was, again, the driest part of the canopy, regardless of orchard site, topography, or row orientation, and the upper eastern position was consistently the wettest.

Timing of dew onset and dry-off. On average, dew onset in the upper eastern canopy occurred $200 \mathrm{~min}$ before dew onset in the lower western canopy (Fig. 3A). Initial dew onset usually was detected between 2200 hours and midnight, but occasionally as late as 0500 hours. On nights when dew was detected by all sensors in a canopy, dew appeared gradually over a period of about $3 \mathrm{~h}$, beginning at the top of the canopy.

Dew dry-off in the upper eastern canopy occurred about $100 \mathrm{~min}$ after the lower western canopy (Fig. 3A). Dry-off usually
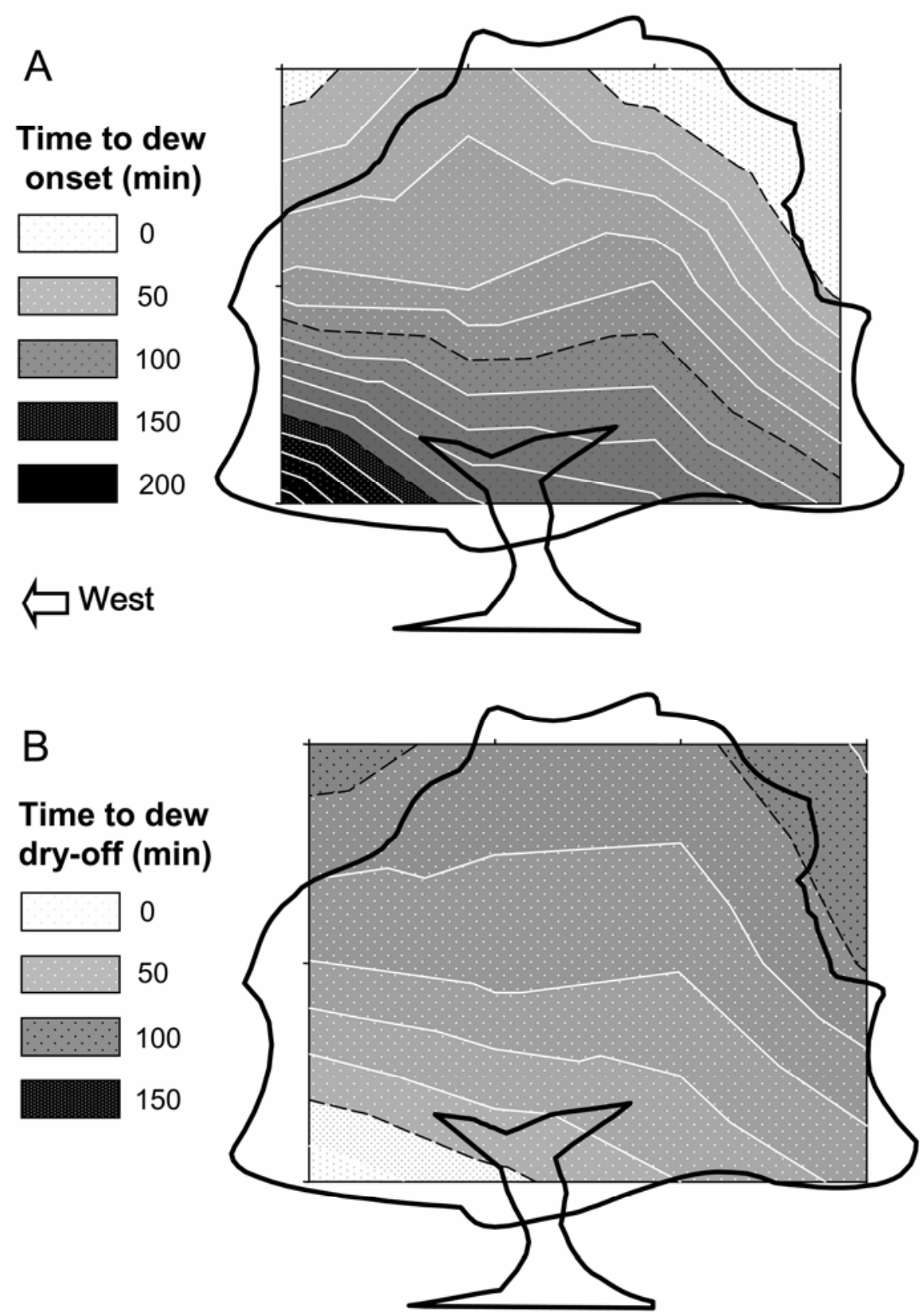

Fig. 3. Timing of A, onset and $\mathbf{B}$, dry-off of dew at 12 canopy positions of four trees in an apple orchard in Gilbert, IA, in 2001. Dew onset was initiated when any canopy location measured wetness for $>30 \mathrm{~min}$. Dew dry-off was initiated when any canopy location that had been wet registered as dry for $>30 \mathrm{~min} / \mathrm{h}$ for $>2$ consecutive hours. Times represent mean lags in onset (A) and dry-off (B) after the first occurrence of these events at any position in the canopy. White lines represent 10-min contours; dotted lines represent 50-min contours.

occurred between 0700 and 0900 hours and usually began in the lower part of the canopy. The entire canopy typically became dry within $2 \mathrm{~h}$. Of 69 dew events in the Gilbert orchard during the 2001 growing season, dew was not detected in the lower western position on 16 nights $(23 \%$ of dew events). In contrast, sensors did not detect dew on two nights $3 \%$ of dew events) in parts of the upper canopy and four to five nights (7\% of dew events) in the middle canopy. Thus, differences in dew onset and dry-off among canopy locations were even more pronounced than indicated in Figure 3, because events when dew did not occur in the lower canopy were not included in the data presented here. The relative scarcity of dew events in the lower western portion of the canopy prevented statistical comparisons of canopy locations for onset and dry-off timing.

Estimation of canopy LWD from sensors over turfgrass. When sensors over turfgrass recorded dew, there was an 86 to $90 \%$ likelihood that the upper eastern canopy of the nearby apple tree canopy was experiencing dew (Table 3). In contrast, the sensors over the turfgrass gave relatively weak estimates of LWD in the driest part of the canopy. Daily mean LWD from sensors placed over turfgrass only slightly overestimated LWD in the top of the apple canopy but greatly overestimated LWD in the lower canopy.

Simulation of warning system using LWD from different canopy positions. Simulation of the Brown-Sutton-Hartman SBFS warning system using LWD data obtained from the wettest portions of the apple canopy resulted in highly conservative second-cover spray recommendations that saved at least one spray compared with a conventional, calendar-based schedule (8) that would apply sprays approximately every 12 days after the firstcover spray (Fig. 4).

Canopy location for LWD measurements influenced the recommended time interval from first- to second-cover fungicide spray by as much as 30 days (Fig. 4). There was a linear relationship between mean daily LWD and days from first- to

Table 3. Correlation $\left(R^{2}\right)$ of daily leaf wetness duration (LWD) measurements over turfgrass with daily LWD in the wettest and driest parts of an apple tree canopy ${ }^{\mathrm{a}}$

\begin{tabular}{llcc}
\hline Year & Orchard & Wettest $^{\mathbf{b}}$ & Driest $^{\mathbf{c}}$ \\
\hline 2000 & Gilbert & 0.87 & 0.68 \\
2001 & Gilbert & 0.90 & 0.77 \\
2003 & Gilbert & 0.89 & 0.57 \\
2003 & Fort Dodge & 0.86 & 0.55 \\
2003 & Cambridge & 0.86 & 0.72 \\
\hline
\end{tabular}

a Measurements made $0.7 \mathrm{~m}$ over turfgrass located 50 to $100 \mathrm{~m}$ from the orchard.

${ }^{b}$ Wettest portion was located in the upper, outer, eastern part of the canopy.

${ }^{c}$ Driest portion of canopy was located in the lower, outer, western part of the canopy. 
second-cover spray. When the days from first- to second-cover fungicide spray of the Brown-Sutton-Hartman system were plotted against mean daily LWD, each additional hour of mean daily LWD resulted in a decrease of 4 to 8 days, depending on site-year. Canopy locations with longer daily LWD had shorter interspray periods than those with shorter daily LWD.

\section{DISCUSSION}

Our data show that apple tree canopies in central Iowa displayed substantial spatial heterogeneity in LWD, and that heterogeneity was more pronounced when wetness resulted from dew than rainfall. In mature semidwarf orchards, only the top of the canopy has unobstructed exposure to the sky and is generally the first area to exhibit wetness during dew events. The daily mean difference in LWD between upper and lower canopy was about $2 \mathrm{~h}$, which is similar to results in Germany (27). Greater dew duration in the upper than the lower canopy occurs because overhanging leaves create a barrier that reduces radiant and convective heat loss from the ground, delaying the cooling of surfaces in the lower canopy and, thereby, delaying dew formation (21). Shorter dew events in the lower canopy were the result not only of later dew onset but also of earlier dry-off than in the upper canopy. East-west differences in LWD were consistent for all study sites on dew days and apparently were related to the westerly winds that prevail in Iowa during the growing season rather than row orientation in the orchard. Compared with dew, rainfall tended to create much more uniform LWD throughout the canopy, reducing but not removing differences among canopy heights. These spatial patterns were consistent for same-cultivar trees of similar size and shape despite differing orchards, row orientation, and growing season.

These data differ from Penrose and Nicol's (20) finding that the center of the apple tree canopy was wet more frequently than the outer canopy in a semiarid region of New South Wales, Australia. This disparity may be related to climatic differences. In arid climates, wetness events are mostly driven by rain whereas, in humid climates, most wetness events are the result of dew (27). Furthermore, Penrose and Nicol collected wetness data four times per day from four sensors per tree, whereas our study recorded data every $5 \mathrm{~min}$ throughout the day from 12 sensors per tree; therefore, we may have detected smaller differences among sites within the canopy.

This study suggests that estimates for LWD hours for the wettest part of the canopy could be obtained consistently from sensors placed either at the top of the canopy or $0.7 \mathrm{~m}$ above nearby turfgrass. More extensive comparisons of sensor readings from the top of several crop canopies to those from nearby sensors located over unobstructed turf support this finding $(21,22)$, and suggest that LWD measurements made over nearby turfgrass sites may be a useful surrogate for implementing the SBFS warning system or other warning systems relying on LWD input data.

The Brown-Sutton-Hartman SBFS warning system $(4,10,11,23,24)$ was developed in North Carolina and Kentucky using LWD sensors placed in the lower canopy. In Iowa, however, this is the most variable location within the tree, according to the present study. Spatial heterogeneity of LWD measurements within the apple canopy could compromise the reliability of this warning system in Iowa and in regions with similar climate. For convenience and economic reasons, many apple growers who monitor LWD for input to warning systems are likely to rely on a single sensor per orchard or per block. In our warning system simulations, sensor location differences of only $0.5 \mathrm{~m}$ in the lower canopy changed recommended timing of the second-cover fungicide spray by $\geq 7$ days. Such discrepancies could lead to inconsistent performance of the warning system, resulting in either excess fungicide sprays or failure to achieve acceptable control of SBFS (1). Our findings emphasize the
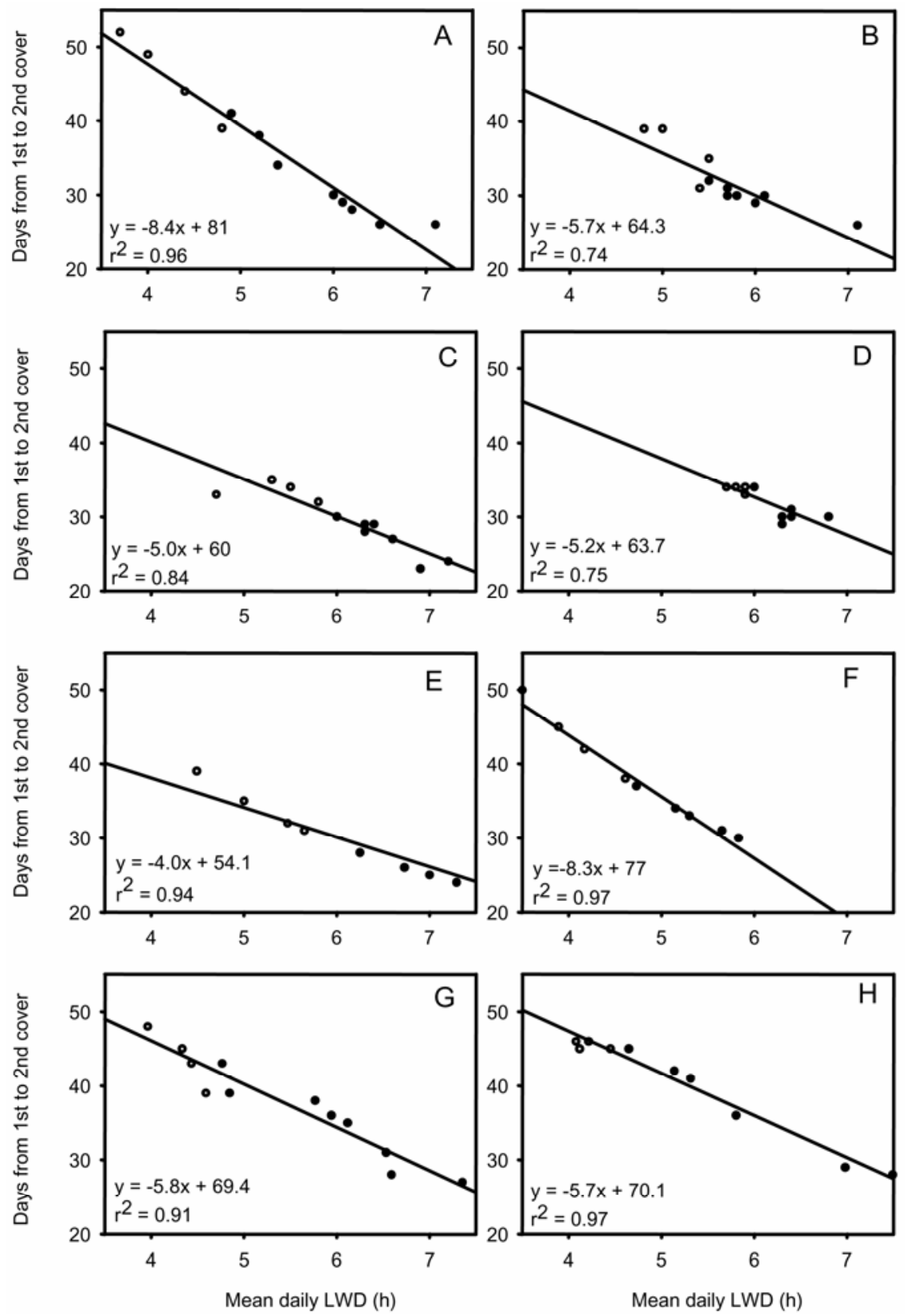

Fig. 4. Simple linear regression mean of daily leaf wetness duration (LWD) at 12 canopy positions in apple trees against the number of days from the first-cover to the second-cover fungicide spray as determined from simulation of the Brown-Sutton-Hartman disease-warning system. Data are from A, $\mathbf{B}, \mathbf{C}$, and D, four trees in a Gilbert, IA orchard during 2001 and from single trees in orchards in E, Cambridge, F, Jefferson, G, Gilbert, and H, Fort Dodge, IA in 2003. Data points with open circles are from the lower canopy. 
importance of accounting for the impact of spatial heterogeneity when in-canopy measurements of LWD are used as inputs to disease-warning systems.

\section{ACKNOWLEDGMENTS}

The project was supported by North Central Region IPM Special Grant \#IOW06656. We thank S. Wegulo, S. Helland, and A. Carlson for technical assistance; and J. Deal of Deal Orchard, G. Baedke of Community Orchard, and S. Black and P. Black of Center Grove Orchard for allowing us to monitor LWD in their orchards.

\section{LITERATURE CITED}

1. Babadoost, M., Gleason, M. L., McManus, P. S., and Helland, S. J. 2004. Evaluation of a wetness-based warning system and reducedrisk fungicides for management of sooty blotch and flyspeck of apple. HortTechnology 14:27-33.

2. Batzer, J. C., Gleason, M. L., Weldon, B., Dixon, P. M., and Nutter, F. W., Jr. 2002. Evaluation of postharvest removal of sooty blotch and flyspeck on apples using sodium hypochlorite, hydrogen peroxide with peroxyacetic acid, and soap. Plant Dis. 86:13251332.

3. Belding, R. D. 1996. Epicuticular wax of apple and its relationship to sooty blotch incidence and captan retention. Ph.D. diss., North Carolina State University, Raleigh.

4. Brown, E. M., and Sutton, T. B. 1995. An empirical model for predicting the first symptoms of sooty blotch and flyspeck on apples. Plant Dis. 79:1165-1168.

5. Cooley, D. R., Gamble. J. W., and Autio, W. R. 1997. Summer pruning as a method for reducing flyspeck disease on apple fruit. Plant Dis. 81:1123-1126.

6. Ellis, M. A., Madden, L. V., and Wilson, L. L. 1998. Evaluation of an empirical model for predicting sooty blotch and flyspeck of apples in Ohio. Pages 21-33 in: Fruit Crops: A Summary of Research. J. S. Scheenes, ed. Ohio Agric. Res. Dev. Ct. Res. Circ. \#299.

7. Garratt, J. R., and Segal, M. 1988. On the contribution to dew formation. BoundaryLayer Meteorol. 45:209-236.

8. Gleason, M. L., Domoto, P. A., Lewis, D. R. 2007. Midwest Commercial Tree Fruit Spray Guide. Iowa State Iowa Extension Service, PM1282.

9. Hall, J. C., Frank, M., Tuttle, A. F., and Cooley, D. R. 1997. Can we predict flyspeck development? Fruit Notes 62(4):21-23.

10. Hartman, J. R. 1995. Evaluation of fungicide timing for sooty blotch and flyspeck control, 1994. Fungic. Nematicide Tests 50:11.

11. Hartman, J. R. 1996. Evaluation of fungicide timing for sooty blotch and flyspeck control, 1995. Fungic. Nematicide Tests 51:6.

12. Huber, L., and Gillespie, T. J. 1992. Modeling leaf wetness in relation to plant disease epidemiology. Annu. Rev. Phytopathol. 30:553-577.

13. Huber, L., and Itier, B. 1990. Leaf wetness in a bean field canopy. Agric. For. Meteorol. 51:281-291.

14. Jacobs, A. F. G., van Boxel, J. H., and ElKilani, R. M. M. 1995. Vertical and horizontal distribution of wind speed and air temperature in a dense vegetation canopy. J. Hydrol. 166:313-326

15. Johnson, E. M., and Sutton, T. B. 2000. Response of two fungi in the apple sooty blotch complex to temperature and relative humidity. Phytopathology 90:362-367.

16. Lau, Y. F., Gleason, M. L., Zriba, N., Taylor, S. E., and Hinz, P. N. 2000. Effects of coating, deployment angle, and compass orientation on performance of electronic sensors during dew periods. Plant Dis. 84:192-197.

17. Leahy, K., Clark, T., and Goodband, E. 2001. Testing various methods of timing summer fungicides. Fruit Notes 63(4):5.
18. Koehler, G. W. 2001. Apple spray materials cost per dose. http://pmo.umext.maine.edu/ apple/AppleSprayDoseCost.pdf.

19. Ocamb-Basu, C. M., and Sutton, T. B. 1988. Effects of temperature on relative humidity on germination, growth, and sporulation of Zygophiala jamaicensis. Phytopathology 78:100103.

20. Penrose, L. J., and Nicol, H. J. 1996. Aspects of microclimate variation within apple tree canopies and between sites in relation to potential Venturia inequalis infection. N.Z. J. Crop Hortic. Sci. 24:259-266.

21. Sentelhas, P. C., Gillespie, T. J., Batzer J. C., Gleason M. L., Monteiro, J. E. B. A, Pezzopane, J. R. M., and Pedro, M. J. 2005. Spatial variability of leaf wetness duration in different crop canopies. Int. J. Biometeorol. 49:363-370

22. Sentelhas, P. C., Gillespie T. J., Gleason M. L., Monteiro, J. E. B. A, and Pezzopane, J. R. M. 2006. Evaluation of a Penman-Monteith approach to provide "reference" and crop canopy leaf wetness duration estimates. Agric. For Meteorol. 141:105-11.

23. Smigell, C. G., and Hartman, J. R. 1997. Evaluation of fungicide timing for sooty blotch and flyspeck control, 1996. Fungic. Nematicide Tests 52:31.

24. Smigell, C. G., and Hartman, J. R. 1998 Evaluation of fungicide timing for sooty blotch and flyspeck control, 1997. Fungic. Nematicide Tests 53:31.

25. Weiss, A., Lukens, D. L., Norman, J. M., and Steadman, J. R. 1989. Leaf wetness in dry beans under semi-arid conditions. Agric. For. Meteorol. 48:149-162.

26. Williamson, S. M., and Sutton, T. B. 2000 Sooty blotch and flyspeck of apple: etiology, biology, and control. Plant Dis. 84:714-724.

27. Wittich, K. P. 1995. Some remarks on dew duration on top of an orchard. Agric. For. Meteorol. 72:167-180. 